Supporting Information for:

\title{
Tentative Confinement of Ionic Liquids in Nylon 6 Fibers: A Bridge Between Structural Developments and High-Performance Properties
}

\author{
Ahmed Dawelbeit and Muhuo Yu* \\ State Key Laboratory for Modification of Chemical Fibers and Polymer Materials, College of Materials Science \\ and Engineering, Donghua University, Shanghai 201620, People's Republic of China. \\ *Corresponding author: Yu Muhuo; yumuhuo@dhu.edu.cn
}




\section{Materials and Methods}

\subsection{Materials}

Nylon 6 pellets $\left(\right.$ Zytel $^{\circledR} 7304$ NC010 obtained by DuPont Company Limited, USA) are dried at vacuum oven. The specific cyano imidazolium bromide IL was supplied by Shanghai ChengJie chemical company and used as received.

\subsection{Fibers preparation}

The nylon 6 pellets and the IL in different percentage weight ratios of IL (0, 1, 2 and $5 \mathrm{wt} \%)$ are co-fed into a single-extruder melt spinning machine (Length to diameter of the screw [L/D] $=25$ ) at melting temperatures of $262-267{ }^{\circ} \mathrm{C}$. The extrudate (hereafter referred to as ILconfined nylon 6) have been spun into fibres through 36 holes spinneret. Afterwards, the spunyet fibers are wound-up on the filament-spool at the take up speed of $515 \mathrm{~m} / \mathrm{min}$ - the winding machine manufactured by Temtec Company Limited of Kyoto, Japan. Subsequently, the spunyet IL-confined nylon 6 fibers have been subjected to a consequent hot drawing process by using a parallel drawing machine - which manufactured by Suzhou Electrical Technology Development Company of China. The drawing temperatures used are 120,140 and $160{ }^{\circ} \mathrm{C}$ and various drawing ratios of the IL-confined nylon 6 fibers. Eventually, the ILs have been extracted out from the IL-confined fibers and the resulting fibers are thermally stabilized. However, out of the total of the confined samples studied, only those which are confined with 2 wt\% IL and hot-drawn at temperatures of $140{ }^{\circ} \mathrm{C}$ and $160{ }^{\circ} \mathrm{C}$ have shown the highest improvements in the tensile strengths and tensile moduli. Moreover, the ILs extraction process is applied to the $2 \%$ IL-confined nylon 6 fibers that had been drawn at a draw ratio of 4.5 and drawing temperatures 140 and $160^{\circ} \mathrm{C}$. However, in the ILs extraction process, the IL-confined fibers are subjected to deionization of ILs by immersing the IL-confined fibers in a $10 \%$ pentahydrate sodium thiosulphate $\left(\mathrm{Na}_{2} \mathrm{~S}_{2} \mathrm{O}_{3} .5 \mathrm{H}_{2} \mathrm{O}\right)$ solution for 12 hours at room temperature, 
and then soaked in a deionized water for one hour. The regenerated nylon 6 fibers are, subsequently, dried in an oven at $50{ }^{\circ} \mathrm{C}$ for one hour. Then, the dried (regenerated) fibers are subjected to thermal stabilisation process by using a heating tube. Afterwards, the regenerated fibers are undergone thermal stabilisation under tension at a heating temperature of $190{ }^{\circ} \mathrm{C}$ for 5 seconds (in the heat treatment process, the running fiber speed is of $12 \mathrm{~m} / \mathrm{min}$ ) under two different tensions of $98 \mathrm{cN}(100 \mathrm{gf})$ and $196 \mathrm{cN}$ (200 gf) at nitrogen ambient.

\subsection{Characterization}

\subsubsection{Fourier transforms infra-red spectroscopy (FTIR)}

The crystalline structure of the neat, the IL-confined and the reverted nylon 6 fibers and their developments due to the deformations processes are evaluated by the Fourier transform Infrared (FTIR) spectrometer (Nicolet 6700 FTIR-ATR - Thermo Fisher Company, USA). The scanning numbers used are 16 for all of the samples with the scanning resolution of 4 and data spacing of $0.482 \mathrm{~cm}^{-1}$. All the FTIR data are fitted by using OMNIC and origin lab softwares.

\subsubsection{Wide Angle X-ray Diffraction (WAXD)}

The crystal and molecular orientation parameters of the neat, IL-confined and reverted nylon 6 fibers are characterized by using wide angle X-ray diffraction (XRD) technique (Rigaku Xray poly-crystal diffractometer - D/max-2550 PC, manufactured by Rigaku, Japan). The $\mathrm{Cu}$

radiation source set with the wavelength of $1.541 \AA$ at voltage of $40 \mathrm{kV}$ and current of 200 $\mathrm{mA}$. The scanning rate is $20^{\circ}(2 \theta) / \mathrm{min}$, and the diffraction patterns are recorded from 2 theta range from $5^{\circ}$ to $60^{\circ}$ with $0.02^{\circ}$ step size.

The degree of crystallinity (which considered as the ratio of the total scatter under the resolved peaks [crystallinity region] to the total scatter under the equatorial peaks), Bragg's interplanar 
spacing $\left(d_{h k l}\right)$, apparent crystallite size (ACS), crystal orientation and crystalline perfection index (CPI) are, also, performed.

\section{Crystallinity}

The crystallinity is considered as the ratio of the total scatter under the resolved peaks (crystallinity region) to the total scatter under the equatorial peaks.

\section{Interplanar spacing}

The Bragg's interplanar spacing is defined by equation 1, below:

$$
d_{h k l}=\frac{\lambda}{2 \sin \theta_{h k l}}
$$

where: $d_{h k l}$ is the interplanar spacing, $\lambda$ is the $\mathrm{x}$-ray wave length $=(1.541 \AA)$ and $\theta_{h k l}$ is the diffraction angle (Bragg's angle).

The apparent crystallite size (ACS)

The apparent crystallite size (ACS) has been calculated from the FHWH of the $\gamma$ and $\alpha$ crystals structure, obtained by Scherrer equation and has been defined by equation 2, below:

$$
\operatorname{ACS}=\frac{\mathrm{K} \lambda}{\beta \cos \theta}
$$

where: ACS is the crystallite size, $\theta$ is the diffraction angle of the equatorial plane, $\lambda$ is the $\mathrm{X}$ ray wave length $=(1.541 \AA)$ and $\mathrm{K}$ is a constant that depends on the crystallite shape and $\beta$ represents the width at the half maximum height (FWHM) of the profile.

\section{Crystal orientation}

The orientation parameter $\left\langle\cos ^{2} \emptyset_{h k l}\right\rangle$ is calculated by equation 3 as follows ${ }^{1-4}$ : 


$$
\left\langle\cos ^{2} \emptyset_{h k l}\right\rangle=\frac{\int_{0}^{\frac{\pi}{2}} I\left(\emptyset_{h k l}\right) \cos \emptyset_{h k l} \cos ^{2} \emptyset_{h k l} d \emptyset_{h k l}}{\int_{0}^{\frac{\pi}{2}} I\left(\emptyset_{h k l}\right) \cos \emptyset_{h k l} d \emptyset_{h k l}}
$$

Where: $\emptyset_{h k l}$ is the azimuthal angle and $\mathrm{I}\left(\varnothing_{h k l}\right)$ is the fully corrected intensity distribution.

The degree of orientation is described by Hermans's crystalline orientation function $f_{c}$ which is defined by equation 4 , below:

$$
f_{C}=\frac{3\left\langle\cos ^{2} \beta\right\rangle-1}{2}
$$

Where; the angle $\beta$ is the angle between the polymer chains axis and the fibers direction.

While, for the monoclinic crystal structure of the nylon 6 fibers, the degree of orientation is calculated with respect to the equator $\left(\emptyset_{h k l}\right)$ by equation 5 , below:

$$
f_{c}=3\left\langle\cos ^{2} \emptyset_{h k l}\right\rangle-2
$$

The relationship between the two orientation parameters can be expressed as in equation 6 (below):

$$
\left\langle\cos ^{2} \beta\right\rangle=2\left\langle\cos ^{2} \emptyset_{h k l}\right\rangle-1
$$

The Hermans's orientation function $\left(f_{c}\right)$ has the values of unity, -0.5 or zero; when the molecular chain of the nylon 6 fibers is paralleled or perpendicular to the fiber axis or the molecular chains are totally unoriented.

\section{Crystalline Perfection Index (CPI)}

The crystalline perfection index (CPI) is calculated form the equation reported by Park, Devries and Statton ${ }^{5}$ (equation 7, below) as follows:

$$
C P I=\frac{\left[\left(d_{200} / d_{002}\right)-1\right]}{0.189} \times 100
$$


Where $d_{200}$ and $d_{002}$ are, respectively, the interplanar lattice spacing for the (200) and the (002) diffraction planes in the equator, and the factor 0.189 is the corresponding value for the ideal crystal structure.

Index of Chain Packing (ICP)

The positions of the (200) and the (002) diffraction planes are used by Murthy, Minor and Latif to define the index of chain packing of the nylon 6 fibers (equation 8, below) as follows:

$$
I C P=\Delta d=(2 \theta)_{002}-(2 \theta)_{200}
$$

Where $\Delta d$ is the difference of the d-spacings of the two intense (200) and (002) equatorial planes.

\subsubsection{The Scanning Electron Microscope (SEM)}

The morphological evaluations of the IL-confined and the reverted nylon 6 fibers are obtained by using the Field-Emission Scanning Electron Microscope (Hitachi SU8010 SEM supplied by Hitachi Company, Japan).

\subsubsection{Mechanical Properties}

The mechanical properties of the neat and IL-confined nylon 6 fibers are performed by the Tensile Strength Testing Machine (XL-2). The clamping distance is $50 \mathrm{~mm}$ for bundles fibers. Whereas, the mechanical properties of the reverted fibers are characterized by the Tensile Strength Testing Machine (XL-1) with clamping of $10 \mathrm{~mm}$ for each single fiber. Both are supplied by Shanghai New Fiber Instrument Limited Company, Shanghai, China. Pneumatic is used for clamping the fibers during the tensile measurement. 


\section{Supplemental Figures}

Generally, in polyamide nylon 6 fibers' formation, the obtained polymorphs have twisted conformation of $\gamma$ phase of the as-spun fibers (parallel hydrogen bonds) and have the zigzagged conformation of $\alpha$ phase of the drawn fibers (anti-parallel hydrogen bonds) ${ }^{6}$. Therefore, in accordance with polyamide chains conformations, hydrogen bonds can be converted between the parallel and the anti-parallel chains by different physical and chemical treatments. The treatments of the parallel chains of nylon 6 result on $\gamma$ phases and the treatments of the antiparallel chains result on $\alpha$ crystalline phases - for the nylon 6 segments.

In this study, the confinement of ILs into nylon 6 by single screw melt-spinning machine is used to form the parallel hydrogen bonding molecules of the as-spun fibers ( $\gamma$ phase) - as a result of which, the phase transitions will form aligned molecules ( $\alpha$ phase) due to the hot drawing - without the need to the additional treatments (annealing). The crystallographic XRD investigations have, also, exhibited the such conclusion - see the following section. Moreover, in this study, the as-spun IL-confined nylon 6 fibers show absorption bands ascribed to $\alpha$ phase structure after hot drawing - in contrast to the complexation treatment of nylon 6 with MMT clay, salts and metal halides, transition metals and rare-earth halides ${ }^{7-10}$.

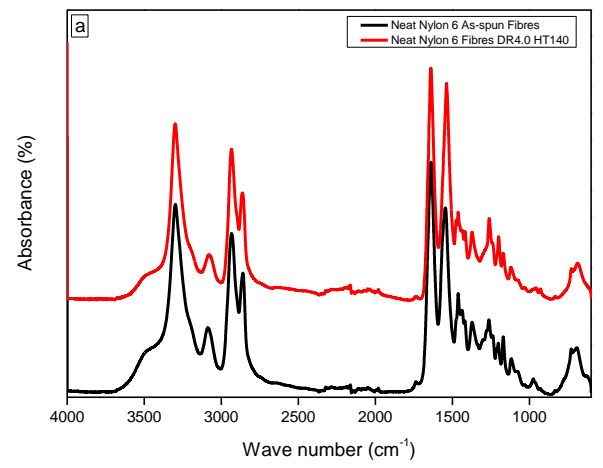



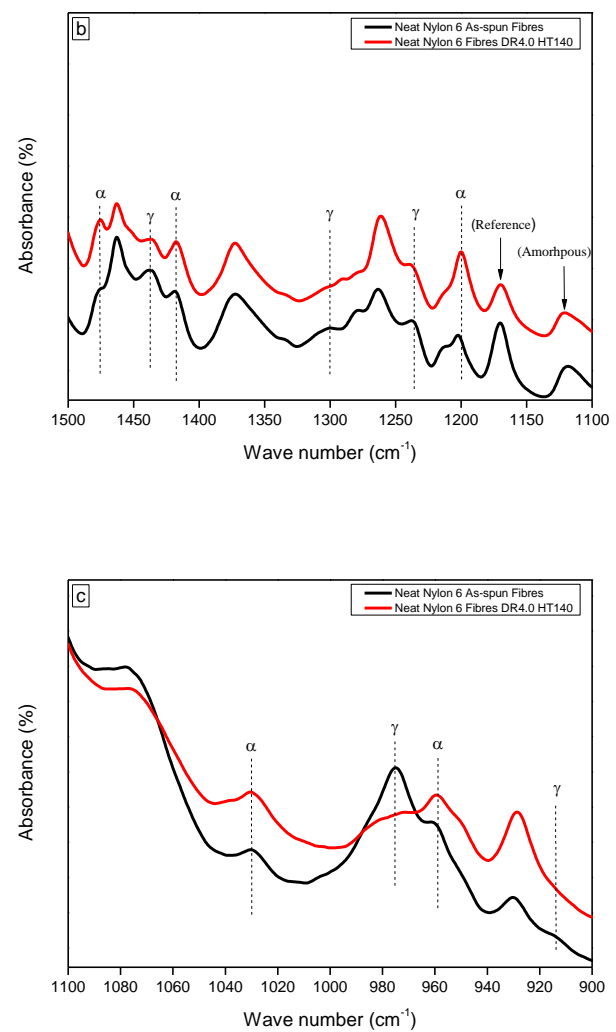

Figure S1: FTIR spectra for the as-spun and the drawn neat nylon 6 fibers, drawn to a maximum drawing ratio of 4.0 at drawing temperature of $140{ }^{\circ} \mathrm{C}$. FTIR spectra at band regions of (a) 4000-600, (b) $1500-1100$ and (c) $1100-900 \mathrm{~cm}^{-1}$, respectively.

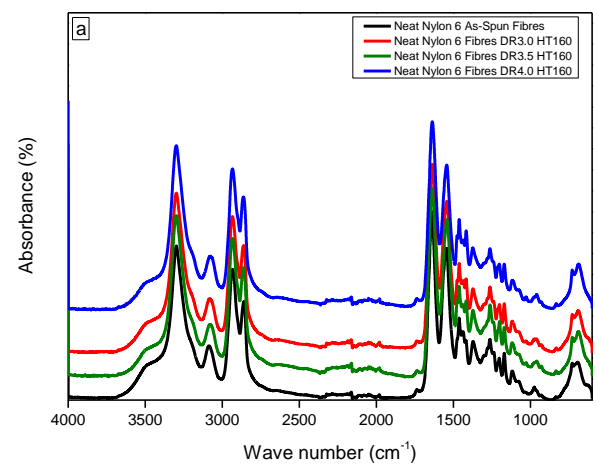



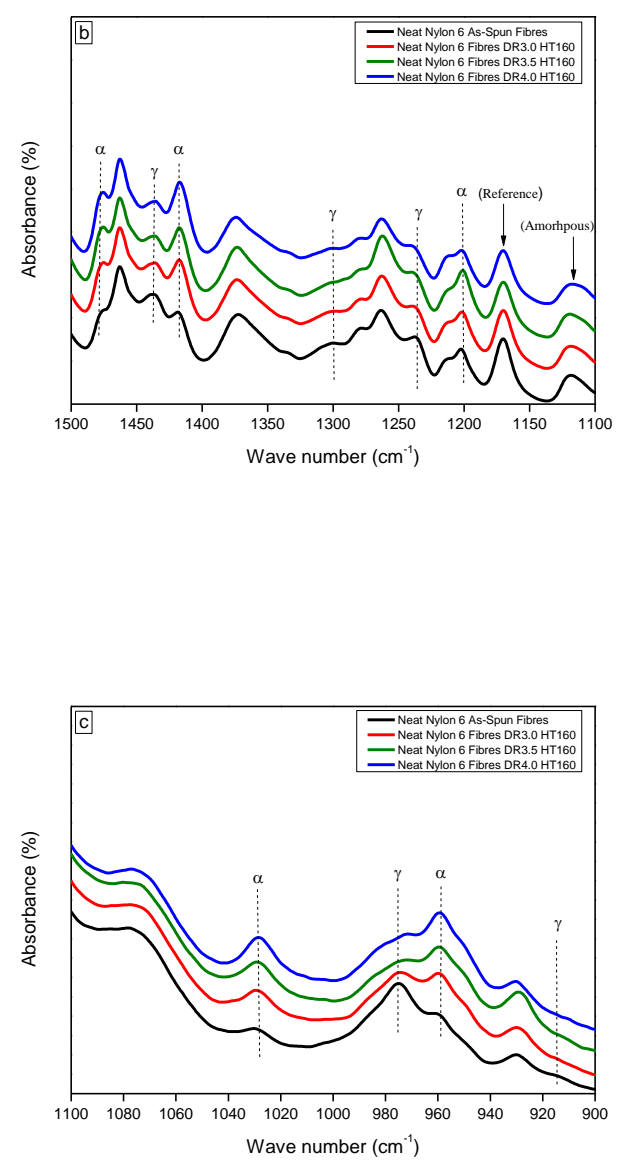

Figure S2: FTIR spectra for the as-spun and the drawn neat nylon 6 fibers, drawn to different drawing ratios at drawing temperature of $160^{\circ} \mathrm{C}$. FTIR spectra at band regions of (a) 4000-600, (b) 1500-1100 and (c) $1100-900 \mathrm{~cm}^{-1}$, respectively.

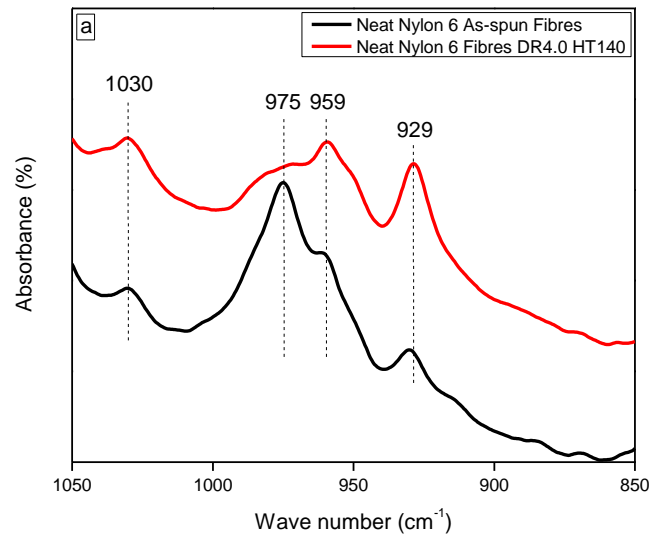




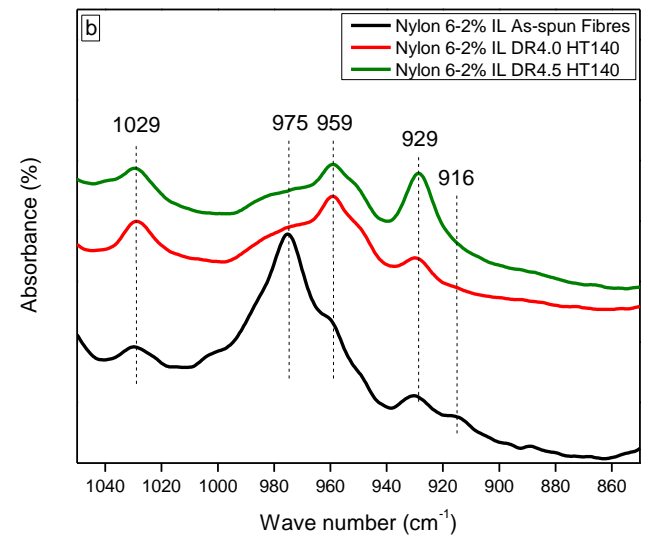

Figure S3: FTIR Spectra at band region of $1050-850 \mathrm{~cm}^{-1}$ for the as-spun and the drawn (a) neat and (b) IL-confined nylon 6 fibers, drawn to different drawing ratios at drawing temperature of $140{ }^{\circ} \mathrm{C}$.
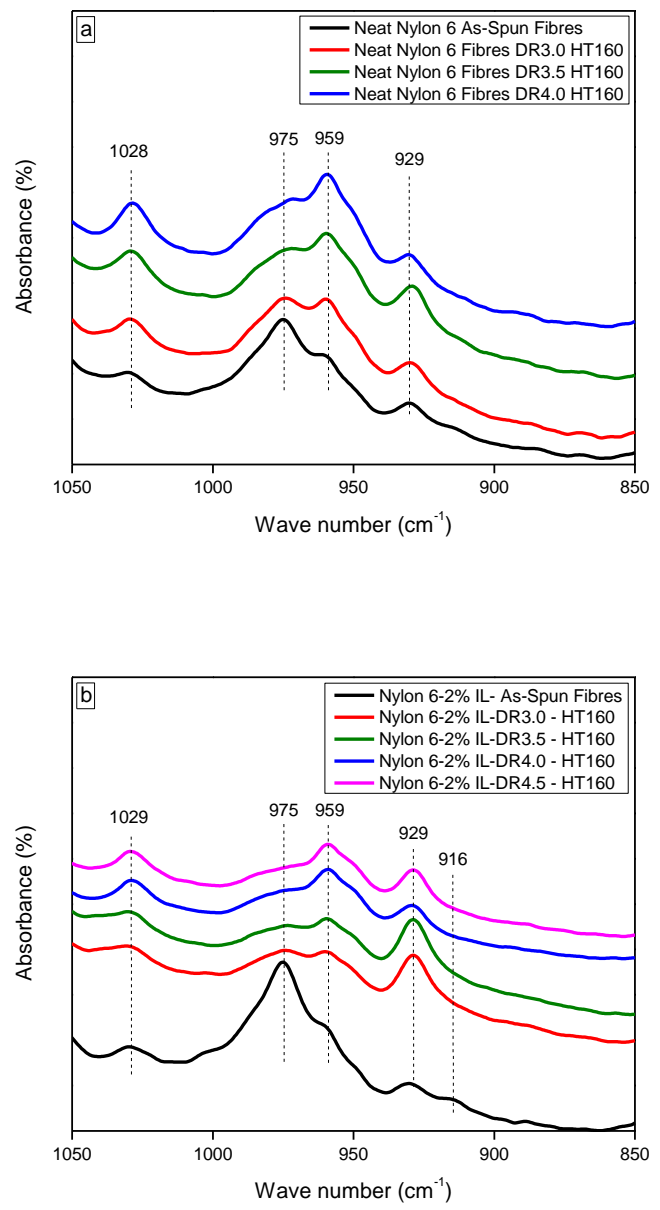

Figure S4: FTIR Spectra at band region of $1050-850 \mathrm{~cm}^{-1}$ for the as-spun and the drawn (a) neat and (b) IL-confined nylon 6 fibers, drawn to different drawing ratios at drawing temperature of $160{ }^{\circ} \mathrm{C}$. 
The FTIR spectra in the wave number range $1050-850 \mathrm{~cm}^{-1}$ and the absorption bands for the as-spun IL-confined nylon 6 fibers have shown high $\gamma$ phase content higher than that for the neat fibers. On other hand, the drawn IL-confined nylon 6 fibers obtained high $\alpha$ phase content than that for the neat nylon 6 ones. One may notice that, the absorption bands at about 930 and $960 \mathrm{~cm}^{-1}$ are attributed to the $\alpha$ phase, while that at 916 and $975 \mathrm{~cm}^{-1}$ are attributed to the $\gamma$ phase. N.B. the as-spun neat nylon 6 fibers did not observed absorption bands at $916 \mathrm{~cm}^{-1}$ for the $\gamma$ phase - see Figures S3 and S4.
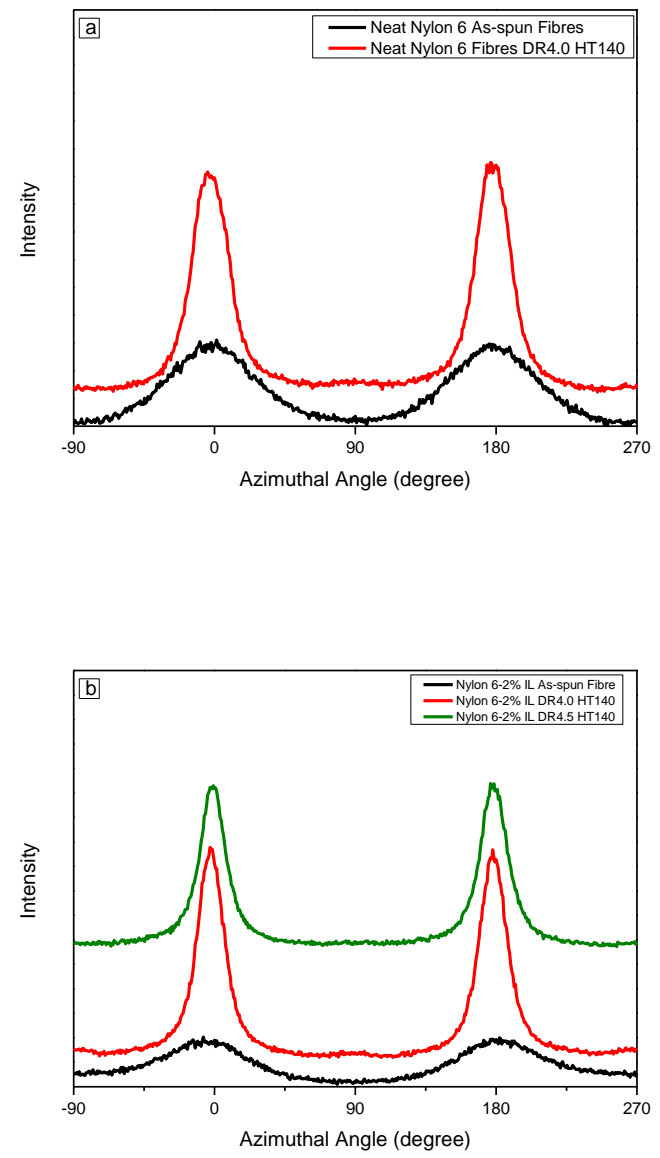

Figure S5: Azimuthal angle of (a) the as-spun and the drawn neat nylon 6 fibers at drawing temperature of $140{ }^{\circ} \mathrm{C}$ and (b) the as-spun and the drawn nylon 6-2\% IL-confined fibers at drawing temperature of $140{ }^{\circ} \mathrm{C}$. 

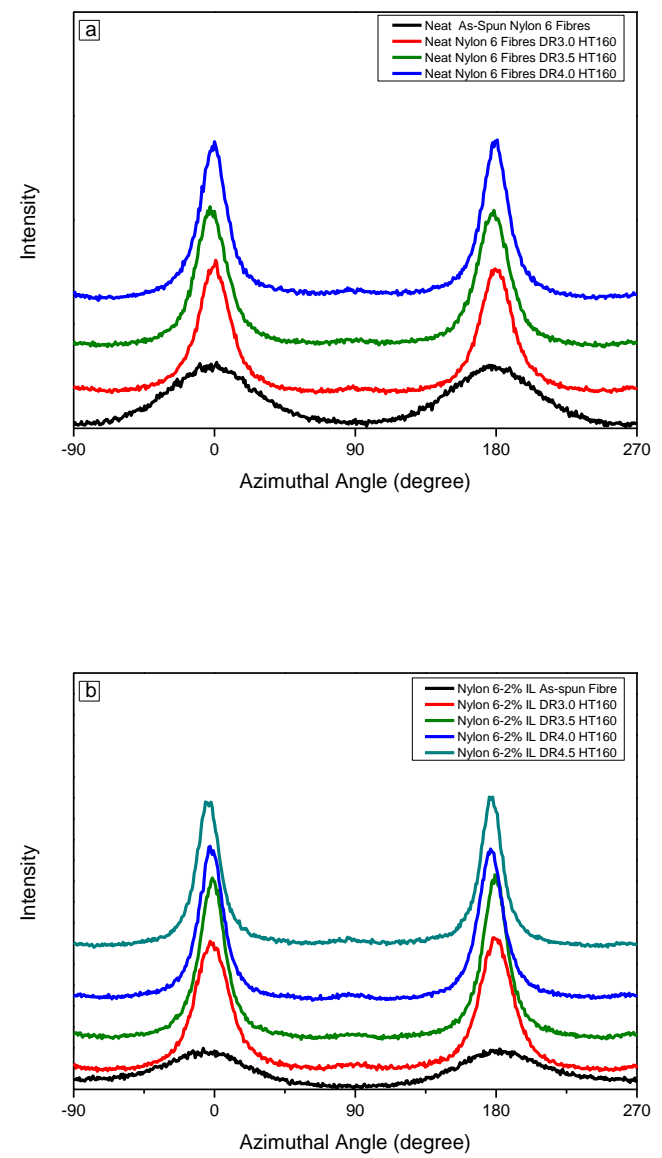

Figure S6: Azimuthal angle of (a) the as-spun and the drawn neat nylon 6 fibers at drawing temperature of $160{ }^{\circ} \mathrm{C}$ and (b) the as-spun and the drawn nylon 6-2\% IL-confined fibers at drawing temperature of $160{ }^{\circ} \mathrm{C}$.

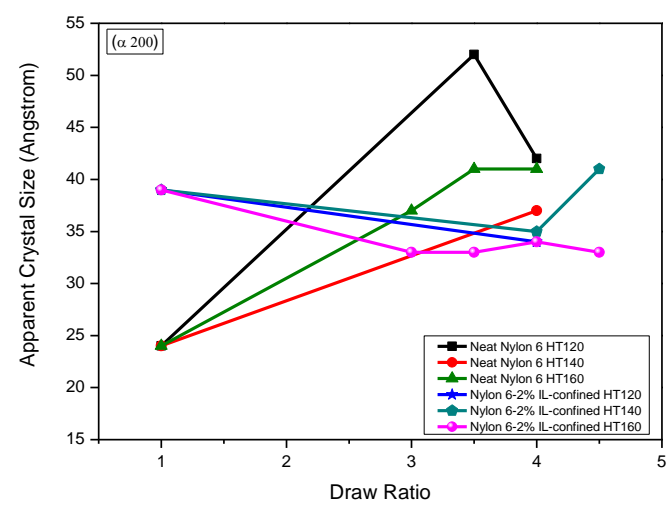

Figure S7: Apparent crystal size (ACS) of the drawn IL-confined nylon 6 fibers at drawing temperatures of 120,140 and $160{ }^{\circ} \mathrm{C}$. 


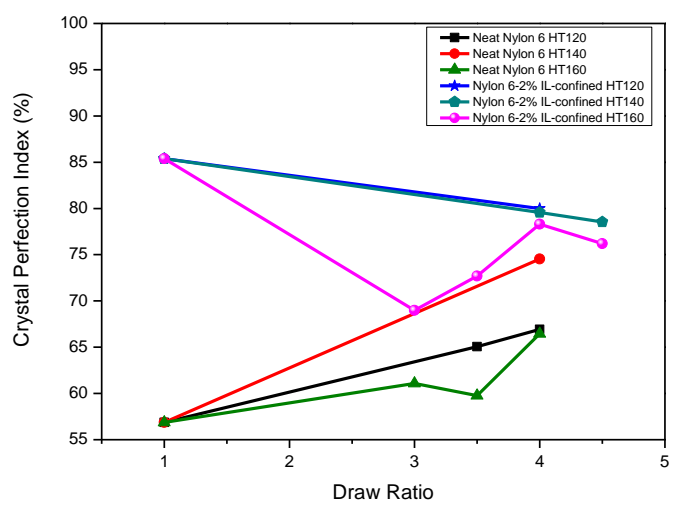

Figure S8: Crystal perfection index (CPI) of the as-spun and drawn neat and IL-confined nylon 6 fibers at drawing temperatures of 120,140 and $160{ }^{\circ} \mathrm{C}$.
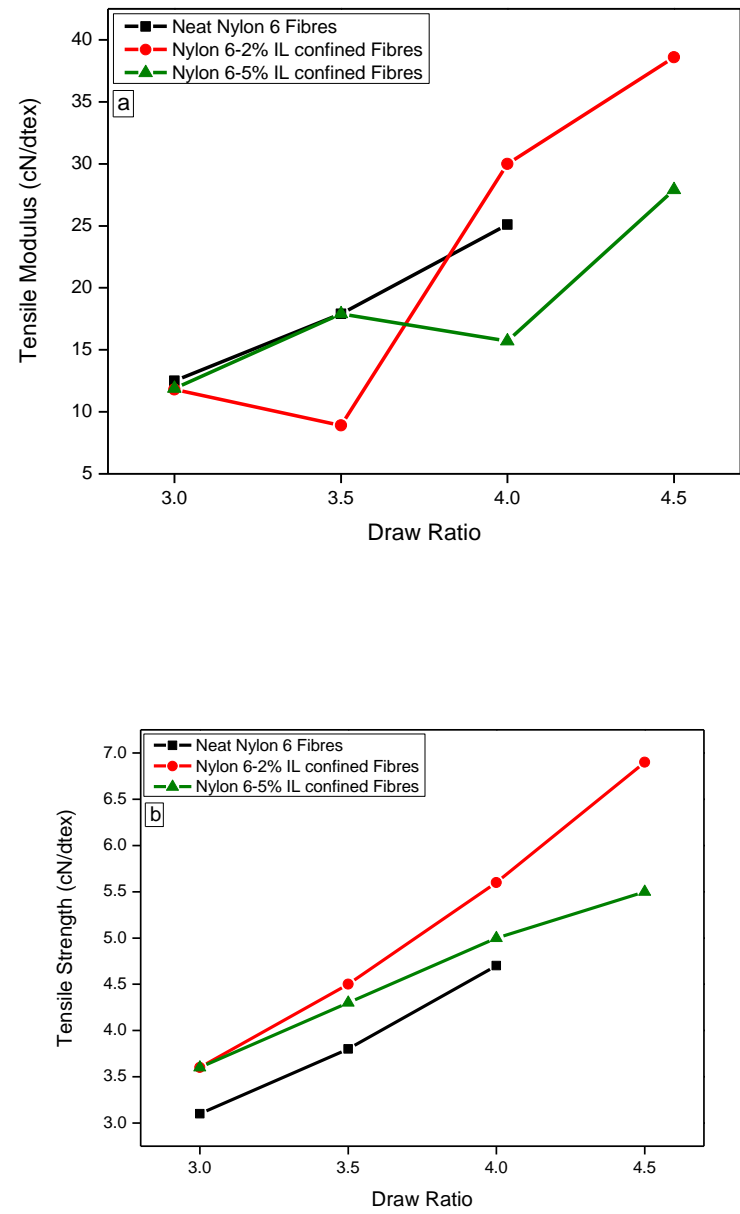


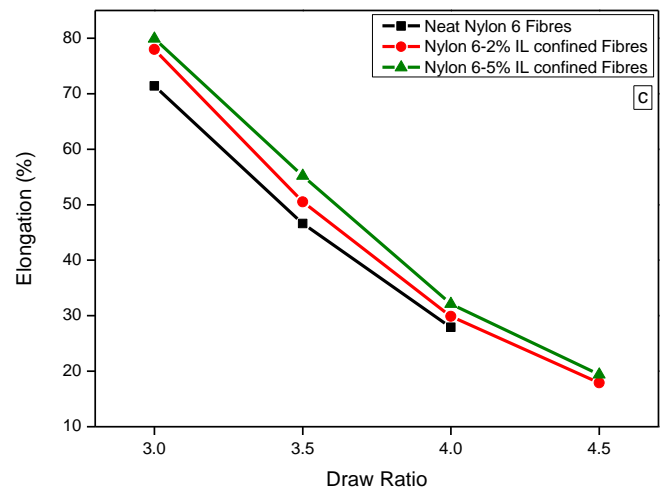

Figure S9: Mechanical properties of the drawn 2 and 5\% IL-confined nylon 6 fibers, (a) Tensile moduli, (b) tensile strength and (c) elongation at different drawing ratios and at drawing temperature of $160{ }^{\circ} \mathrm{C}$.
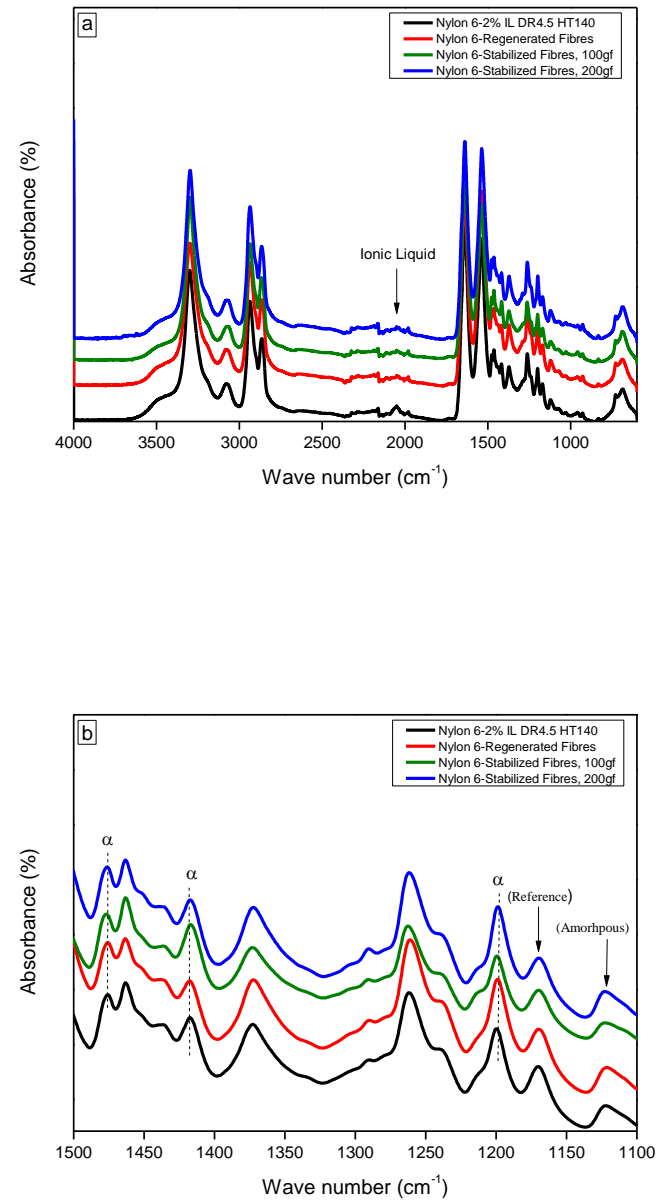


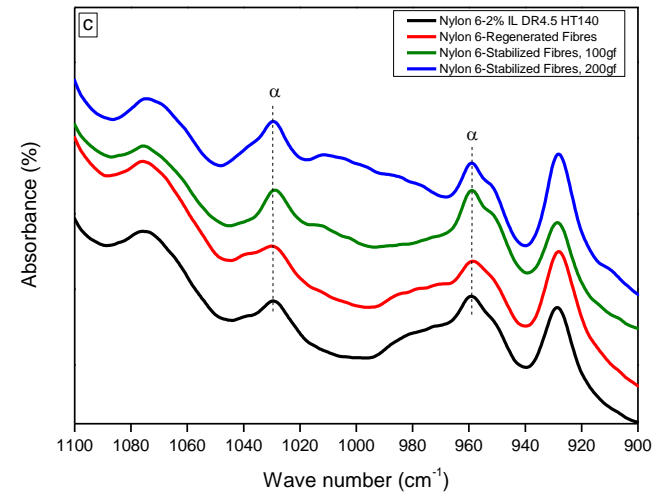

Figure S10: FTIR spectra of the IL-confined (2\% IL-confined nylon 6 fibers, DR4.5 HT140), regenerated and stabilized nylon 6 fibers at band regions of (a) 4000-600, (b) 1500-1100 and (c) 1100$900 \mathrm{~cm}^{-1}$, respectively.
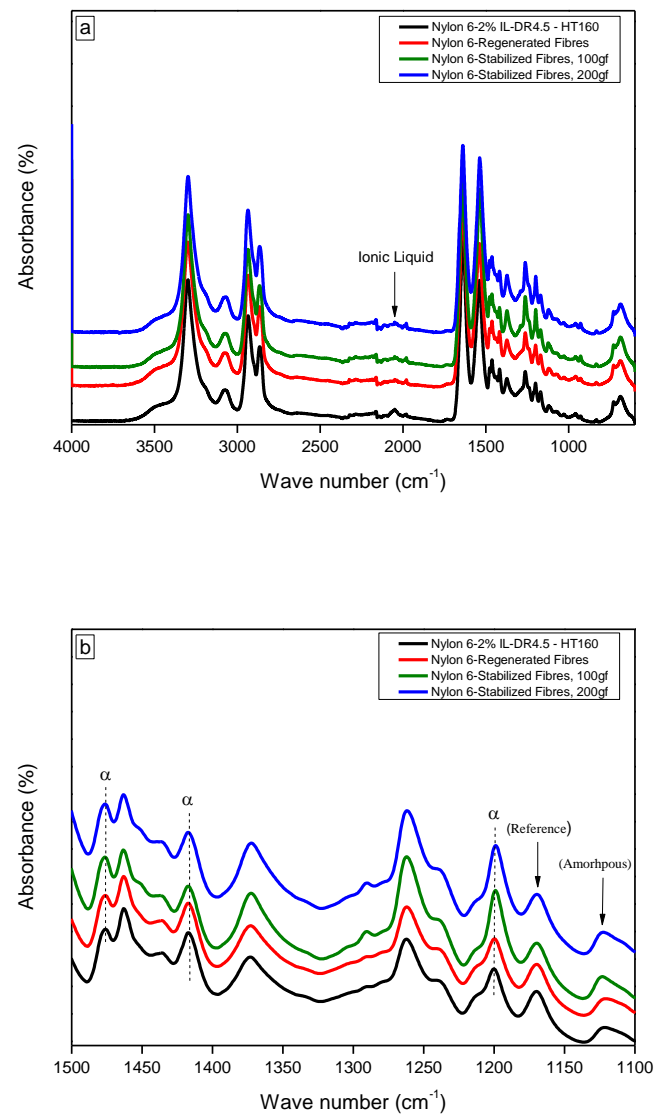


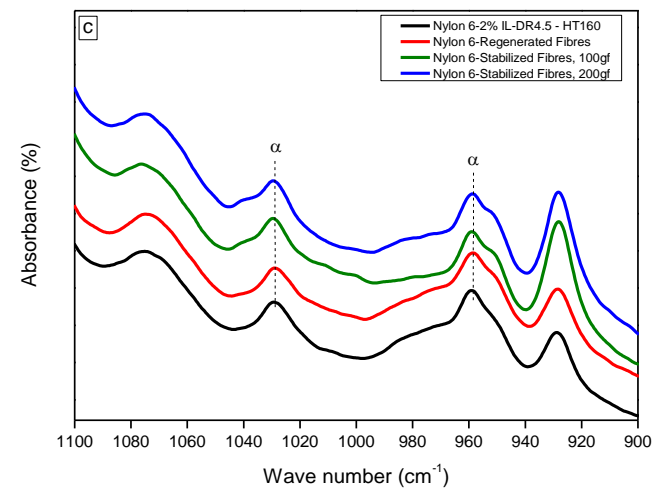

Figure S11: FTIR spectra of the IL-confined (2\% IL-confined nylon 6 fibers, DR4.5 HT160), regenerated and stabilized nylon 6 fibers at band regions of (a) 4000-600, (b) 1500-1100 and (c) 1100$900 \mathrm{~cm}^{-1}$, respectively.
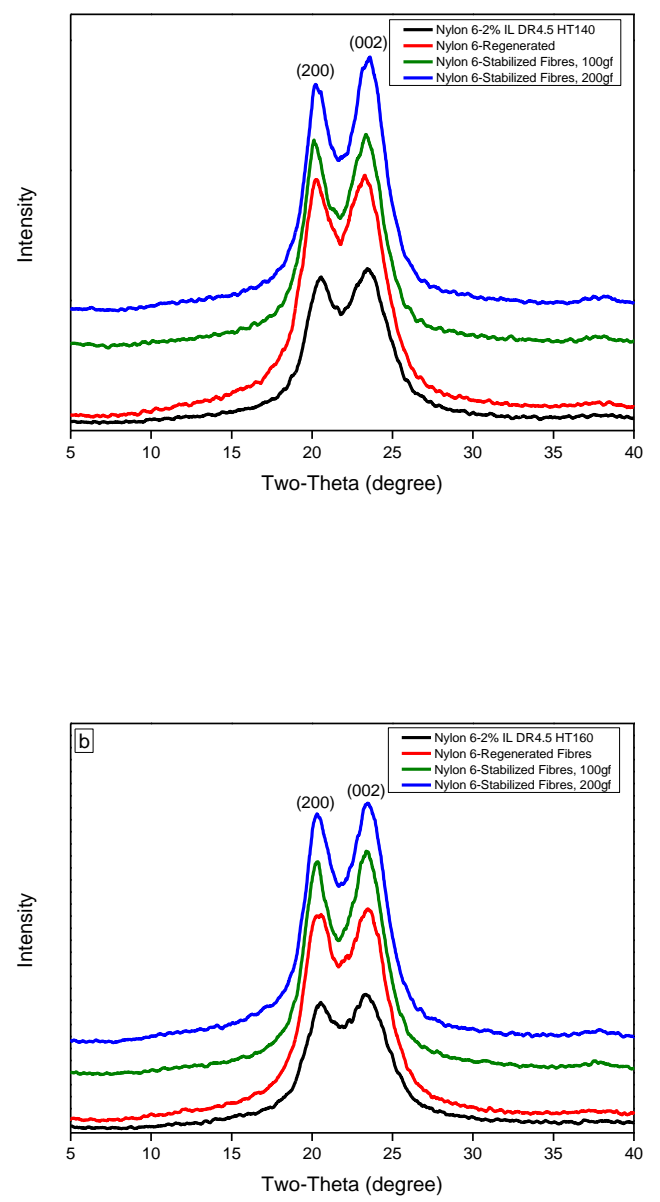

Figure S12: XRD equatorial diffraction patterns of (a) the IL-confined (2\% IL-confined nylon 6 fibers, DR4.5 HT140), regenerated and stabilized nylon 6 fibers and (b) the IL-confined (2\% IL-confined nylon 6 fibers, DR4.5 HT160), regenerated and stabilized nylon 6 fibers. 


\section{Supplemental Tables}

Table S1: Crystalline Structural Properties of the Drawn Neat and 2\% IL-confined Nylon 6 Fibers at $140{ }^{\circ} \mathrm{C}$.

\begin{tabular}{|c|c|c|c|c|c|c|c|c|c|c|}
\hline \multirow[t]{2}{*}{ Samples } & \multirow[t]{2}{*}{$\begin{array}{l}\text { Crystallinity } \\
\qquad \%)\end{array}$} & \multirow{2}{*}{$\begin{array}{l}\text { Crystal } \\
\text { perfection } \\
\text { Index } \\
(\mathrm{CPI})(\%)\end{array}$} & \multicolumn{2}{|c|}{$\begin{array}{c}\text { Index of Crystalline } \\
\text { Perfection [chain packing] } \\
\text { (ICP) }\end{array}$} & \multicolumn{2}{|c|}{$\begin{array}{l}\text { Apparent } \\
\text { Crystal Size } \\
(\text { ACS })(\AA)\end{array}$} & \multirow[t]{2}{*}{$\left\langle\cos ^{2} \emptyset_{\mathrm{hkl}}\right.$} & \multirow{2}{*}{$\left\langle\cos ^{2} \beta\right\rangle$} & \multirow{2}{*}{$\begin{array}{l}\text { Degree of } \\
\text { orientation } \\
\qquad\left(f_{c}\right)\end{array}$} & \multirow[t]{2}{*}{$\begin{array}{c}\text { Orientation } \\
\text { Angle }\end{array}$} \\
\hline & & & $\Delta 2 \theta$ & $\Delta \mathrm{d}$ & 200 & 002 & & & & \\
\hline $\begin{array}{l}\text { Neat Nylon } 6 \\
\text { DR4.0 HT140 }\end{array}$ & 59.15 & 74.544 & 2.903 & 0.5389 & 37 & 28 & 0.973 & 0.946 & 0.919 & 13.41 \\
\hline $\begin{array}{l}\text { Nylon 6-2\% IL } \\
\text { DR4.0 HT140 }\end{array}$ & 67.17 & 79.58 & 3.113 & 0.5681 & 35 & 30 & 0.974 & 0.947 & 0.921 & 13.28 \\
\hline $\begin{array}{l}\text { Nylon 6-2\% IL } \\
\text { DR4.5 HT140 }\end{array}$ & 72.20 & 78.54 & 3.069 & 0.5619 & 41 & 28 & 0.973 & 0.946 & 0.919 & 13.46 \\
\hline
\end{tabular}


Table S2: Crystalline Structural Properties of the Drawn Neat and 2\% IL-confined Nylon 6 Fibers at $160{ }^{\circ} \mathrm{C}$.

\begin{tabular}{|c|c|c|c|c|c|c|c|c|c|c|}
\hline Samples & $\begin{array}{l}\text { Crystallinity } \\
\qquad \%)\end{array}$ & $\begin{array}{c}\text { Crystal } \\
\text { perfection } \\
\text { Index (CPI) } \\
(\%)\end{array}$ & \multicolumn{2}{|c|}{$\begin{array}{c}\text { Index of Crystalline } \\
\text { Perfection [chain packing] } \\
\text { (ICP) }\end{array}$} & \multicolumn{2}{|c|}{$\begin{array}{c}\text { Apparent } \\
\text { Crystal Size } \\
(\text { ACS })(\AA)\end{array}$} & $\left\langle\cos ^{2} \emptyset_{\mathrm{hkl}}\right\rangle$ & $\left\langle\cos ^{2} \beta\right\rangle$ & $\begin{array}{l}\text { Degree of } \\
\text { orientation } \\
\quad\left(f_{c}\right)\end{array}$ & $\begin{array}{c}\text { Orientatior } \\
\text { Angle }\end{array}$ \\
\hline $\begin{array}{l}\text { Neat Nylon } 6 \\
\text { DR } 3.0 \text { HT } 160\end{array}$ & 57.48 & 61.09 & 2.406 & 0.4464 & 37 & 35 & 0.961 & 0.921 & 0.881 & 16.33 \\
\hline $\begin{array}{l}\text { Neat Nylon } 6 \\
\text { DR } 3.5 \text { HT } 160\end{array}$ & 59.10 & 59.778 & 2.554 & 0.4765 & 41 & 37 & 0.969 & 0.939 & 0.908 & 14.36 \\
\hline $\begin{array}{l}\text { Neat Nylon } 6 \\
\text { DR 4.0 HT } 160\end{array}$ & 56.26 & 66.45 & 2.603 & 0.4841 & 41 & 38 & 0.949 & 0.899 & 0.848 & 18.54 \\
\hline $\begin{array}{l}\text { Nylon 6-2\% IL } \\
\text { DR3.5 HT160 }\end{array}$ & 64.01 & 72.703 & 2.863 & 0.5214 & 33 & 30 & 0.972 & 0.943 & 0.915 & 13.81 \\
\hline $\begin{array}{l}\text { Nylon 6-2\% IL } \\
\text { DR4.0 HT160 }\end{array}$ & 80.81 & 78.305 & 3.041 & 0.564 & 34 & 29 & 0.981 & 0.962 & 0.943 & 11.22 \\
\hline $\begin{array}{c}\text { Nylon 6-2\% IL } \\
\text { DR4.5HT160 }\end{array}$ & 63.60 & 76.184 & 2.984 & 0.5461 & 33 & 30 & 0.987 & 0.974 & 0.961 & 9.29 \\
\hline
\end{tabular}




\begin{tabular}{|c|c|c|c|c|c|c|c|c|c|c|}
\hline \multirow[t]{2}{*}{ Samples } & \multirow[t]{2}{*}{$\begin{array}{c}\text { Treatment } \\
\text { Temperature } \\
\left({ }^{\circ} \mathrm{C}\right)\end{array}$} & \multirow[t]{2}{*}{$\begin{array}{l}\text { Tension } \\
(\mathrm{cN})\end{array}$} & \multirow[t]{2}{*}{$\begin{array}{c}\text { Crystallinity } \\
(\%)\end{array}$} & \multirow{2}{*}{$\begin{array}{c}\text { Crystal } \\
\text { Perfection } \\
\text { Index, CPI } \\
(\%)\end{array}$} & \multicolumn{2}{|c|}{$\begin{array}{c}\text { Apparent } \\
\text { Crystal } \\
\text { Size, ACS } \\
(\AA) \\
\end{array}$} & \multirow[t]{2}{*}{$\cos ^{2} \emptyset_{\mathrm{hkl}}$} & \multirow[t]{2}{*}{$\left\langle\cos ^{2} \beta\right\rangle$} & \multirow[t]{2}{*}{$\begin{array}{c}\text { Degree of } \\
\text { Orientation } \\
\qquad\left(f_{c}\right)\end{array}$} & \multirow[t]{2}{*}{$\begin{array}{l}\text { Orientation } \\
\text { Angle } \\
\text { (degree) }\end{array}$} \\
\hline & & & & & 200 & 002 & & & & \\
\hline $\begin{array}{c}\text { Nylon 6-2\% IL-Confined Fibers, DR4.5 } \\
\text { HT140 }\end{array}$ & 140 & DR4.5 & 72.20 & 78.54 & 41 & 28 & 0.973 & 0.946 & 0.919 & 13.46 \\
\hline Regenerated Nylon 6 Fibers, SDES-00z-1\# & $\begin{array}{c}\text { Room } \\
\text { Temperature }\end{array}$ & $\begin{array}{c}\text { Free- } \\
\text { Tension }\end{array}$ & 66.50 & 78.693 & 37 & 30 & 0.953 & 0.906 & 0.859 & 17.85 \\
\hline Stabilized Nylon 6 Fibers, SDES-1\#-100 & 190 & 98 & 73.33 & 82.620 & 39 & 33 & 0.934 & 0.867 & 0.802 & 21.30 \\
\hline Stabilized Nylon 6 Fibers, SDES-1\#-200 & 190 & 196 & 71.27 & 85.162 & 42 & 34 & 0.971 & 0.942 & 0.914 & 13.90 \\
\hline $\begin{array}{c}\text { Nylon 6-2\% IL-Confined Fibers, DR4.5 } \\
\text { HT160 }\end{array}$ & 160 & DR4.5 & 63.60 & 76.184 & 33 & 30 & 0.987 & 0.974 & 0.961 & 9.29 \\
\hline Regenerated Nylon 6 Fibers, SDES-00z-2\# & $\begin{array}{c}\text { Room } \\
\text { Temperature }\end{array}$ & $\begin{array}{l}\text { Free- } \\
\text { Tension }\end{array}$ & 68.38 & 82.682 & 39 & 29 & 0.963 & 0.925 & 0.888 & 15.88 \\
\hline Stabilized Nylon 6 Fibers, SDES-2\#-100 & 190 & 98 & 76.22 & 84.651 & 43 & 32 & 0.950 & 0.899 & 0.849 & 18.52 \\
\hline Stabilized Nylon 6 Fibers, SDES-2\#-200 & 190 & 196 & 72.28 & 85.134 & 40 & 33 & 0.973 & 0.946 & 0.919 & 13.42 \\
\hline
\end{tabular}




\section{References:}

1. Heuvel, H. M.; Huisman, R., Five-line model for the description of radial x-ray diffractometer scans of nylon 6 yarns. J. Polym. Sci., Polym. Phys. Ed. 1981, 19 (1), 121-134.

2. Stein, R. S.; Wilkes, G. L., Physico-Chemical Approaches To The Measurement Of Anisotropy. In Structure and Properties of Oriented Polymers, Ward, I. M., Ed. Springer Science+Business Media, B. V.: England, 1975; pp 57-149.

3. Alexander, L. E., X-Ray Diffraction Methods in Polymer Science. John Wiley \& Sons: New York, 1969.

4. Wilchinsky, Z. W., Measurement of Orientation in Polypropylene Film. J. Appl. Phys. 1960, 31 (11), 1969-1972.

5. Park, J. B.; Devries, K. L.; Station, W. O., Structure changes caused by strain annealing of nylon 6 fibers. J. Macromol. Sci., Part B: Phys. 1978, 15 (2), 229-256.

6. Murthy, N. S.; Szollosi, A. B.; Sibilia, J. P.; Krimm, S., Structure of iodide ion arrays in iodinated nylon 6 and the chain orientation induced by iodine in nylon 6 films. J. Polym. Sci., Polym. Phys. Ed. 1985, 23 (11), 2369-2376.

7. Hasani, Z.; Youssefi, M.; Borhani, S.; Mallakpour, S., Structure and properties of nylon6/amino acid modified nanoclay composite fibers. J. Text. Inst. 2019, 110 (9), 1336-1342.

8. Levchik, S. V.; Weil, E. D.; Lewin, M., Thermal decomposition of aliphatic nylons. Polym. Int. 1999, 48 (7), 532-557.

9. $\quad$ Liu, S.; Zhang, C.; Proniewicz, E.; Proniewicz, L. M.; Kim, Y.; Liu, J.; Zhao, Y.; Xu, Y.; $\mathrm{Wu}, \mathrm{J} .$, Crystalline transition and morphology variation of polyamide $6 / \mathrm{CaCl} 2$ composite during the decomplexation process. Spectrochim. Acta, Part A 2013, 115, 783-788.

10. Liu, S.; Zhang, C.; Liu, Y.; Zhao, Y.; Xu, Y.; Ozaki, Y.; Wu, J., Coordination between yttrium ions and amide groups of polyamide 6 and the crystalline behavior of polyamide $6 / y$ ttrium composites. J. Mol. Struct. 2012, 1021, 63-69. 